\title{
A numerical approach for a nonhomogeneous differential equation with variable delays
}

\author{
Mustafa Özel ${ }^{1}$ (1) $\cdot$ Mehmet Tarakçı ${ }^{2} \cdot$ Mehmet Sezer $^{3}$
}

Received: 13 December 2017 / Accepted: 26 May 2018/ Published online: 5 June 2018

(C) The Author(s) 2018

\begin{abstract}
In this study, we consider a linear nonhomogeneous differential equation with variable coefficients and variable delays and present a novel matrix-collocation method based on Morgan-Voyce polynomials to obtain the approximate solutions under the initial conditions. The method reduces the equation with variable delays to a matrix equation with unknown MorganVoyce coefficients. Thereby, the solution is obtained in terms of Morgan-Voyce polynomials. In addition, two test problems together with error analysis are performed to illustrate the accuracy and applicability of the method; the obtained results are scrutinized and interpreted by means of tables and figures.
\end{abstract}

Keywords Morgan-Voyce polynomials · Matrix method $\cdot$ Collocation method $\cdot$ Delay differential equation . Variable delay

\section{Introduction}

In this paper, we consider nonhomogeneous differential equation with variable delays in the form $[3,5,10,12$, $23,30,37,38]$.

$y^{\prime}(t)=P_{o}(t)+P_{1}(t) y(t)+\sum_{j=2}^{m} P_{j}(t) y\left(t-\tau_{j}(t)\right)$

under the initial condition $y(a)=\lambda$, where the coefficients $P_{j}(t)$ and the delays $\tau_{j}$ are continuous functions on the interval $0 \leq a \leq j \leq b$ and the delays are nonnegative, $\tau_{j}(t) \geq 0$ for $t \geq a$.

Delay differential equations of the type 1 arise in a variety of applications including control systems, electrodynamics, mixing liquids, neutron transportation, population models, physiological processes and conditions

Mustafa Özel

mustafa.ozel@deu.edu.tr

1 Department of Geophysical Engineering, Faculty of Engineering, Dokuz Eylul University, Tinaztepe Campus, Buca, 35160 İzmir, Turkey

2 Department of Physics, Faculty of Science, Dokuz Eylul University, Tınaztepe Campus, Buca, 35160 İzmir, Turkey

3 Department of Mathematics, Faculty of Art and Science, Celal Bayar University, Manisa, Turkey including production of blood cells $[1,14,23,25$, $27,28,34,37]$.

In the case of bounded delays, many authors using standard techniques $[3,10,20,27,34,37]$ have studied the asymptotic behavior of solutions, the asymptotic stability in equations and the existence of positive periodic solutions of delay equations. However, most of the mentioned type delay equations have not analytical and numerical solutions; therefore, numerical methods are required to obtain approximate solutions. For this purpose, by means of the matrix method based on collocation points which have been given by Sezer and coworkers $[2,6,16,17,21$, $26,29,36]$, we develop a novel matrix technique to find the approximate solution of Eq. 1 under the initial condition $y(a)=\lambda$ in the truncated Morgan-Voyce series form

$y(t) \cong y_{N}(t)=\sum_{n=0}^{N} y_{n} b_{n}(t), a \leq t \leq b$

where $y_{n}, n=0,1, \ldots, N$ are coefficients to be determined; $b_{n}, n=0,1, \ldots, N$ are the first kind Morgan-Voyce polynomials defined by $[11,32,33]$

$$
b_{n}(t)=\sum_{j=0}^{n}\left(\begin{array}{l}
n+j \\
n-j
\end{array}\right) t^{j}, \quad n \in \mathrm{N}, \quad a \leq t \leq b
$$


Here, the set of polynomials $\left\{b_{n}(t)\right\}$ has the following properties [11, 15, 19, 32]

1. The polynomials $b_{n}(t)$ defined by 3 are recursively given by the relation

$b_{n}(t)=(t+2) b_{n-1}(t)-b_{n-2}(t), \quad n \geq 2$

with $b_{o}(t)=1$ and $b_{n}(t)=t+1$.

2. The polynomials $y=b_{n}(t), n=0,1, \ldots$ are solutions of the differential equation

$t(t+4) y^{\prime \prime}+2(t+1) y^{\prime}-n(n+1) y=0$.

3. The first four Morgan-Voyce polynomials of the first kind are obtained from 3 as

$$
\begin{aligned}
& b_{o}(t)=1, b_{1}(t)=t+1, b_{2}(t)=t^{2}+3 t+1, \\
& b_{3}(t)=t^{3}+5 t^{2}+6 t+1, \ldots
\end{aligned}
$$

\section{Fundamental matrix relations}

In this section, we compose the matrix relations of Eq. 1 and its solution Eq. 2. For this aim, we first write the matrix form of the finite Morgan-Voyce series Eq. 2 as

$y(t) \cong y_{N}(t)=b(t) Y$

so that

$$
\begin{aligned}
b(t) & =\left[b_{o}(t), b_{1}(t), \ldots, b_{N}(t)\right] \\
Y & =\left[y_{o}, y_{1}, \ldots, y_{N}\right]^{T} ;
\end{aligned}
$$

then, by using the Morgan-Voyce polynomials Eq. 3, we obtain the matrix form $b(t)$ as follows

$b(t)=X(t) M$

where

$X(t)=\left[1, t, t^{2}, \ldots, t^{N}\right]$ and

$$
M=\left[\begin{array}{ccccc}
\left(\begin{array}{l}
0 \\
0
\end{array}\right) & \left(\begin{array}{l}
1 \\
1
\end{array}\right) & \left(\begin{array}{l}
2 \\
2
\end{array}\right) & \ldots & \left(\begin{array}{c}
N \\
N
\end{array}\right) \\
0 & \left(\begin{array}{l}
2 \\
0
\end{array}\right) & \left(\begin{array}{l}
3 \\
1
\end{array}\right) & \ldots & \left(\begin{array}{c}
N+1 \\
N-1
\end{array}\right) \\
0 & 0 & \left(\begin{array}{l}
4 \\
0
\end{array}\right) & \ldots & \left(\begin{array}{c}
N+2 \\
N-2
\end{array}\right) \\
\vdots & \vdots & \vdots & & \vdots \\
0 & 0 & 0 & \ldots & \left(\begin{array}{c}
2 N \\
0
\end{array}\right)
\end{array}\right]
$$

Besides, the relation between the matrix and its derivative $X^{\prime}(t)$ can be written in the form [13, 18, 22, 24]

$X^{\prime}(t)=X(t) T$

where

$$
T=\left[\begin{array}{ccccc}
0 & 1 & 0 & \ldots & 0 \\
0 & 0 & 2 & \ldots & 0 \\
\vdots & \vdots & \vdots & & \vdots \\
0 & 0 & 0 & \ldots & N \\
0 & 0 & 0 & \ldots & 0
\end{array}\right] .
$$

Then, by means of the matrix relations Eqs. 4, 5, and 6, we obtain

$$
\begin{aligned}
y(t) & \cong y_{N}(t)=b(t) Y \\
& =X(t) M Y
\end{aligned}
$$

and

$$
\begin{aligned}
y^{\prime}(t) & \cong y_{N}^{\prime}(t)=X^{\prime}(t) M Y \\
& =X(t) T M Y
\end{aligned}
$$

By putting $t \rightarrow t-\tau_{j}(t)$ in Eq. 7, we gain the recurrence relation $[13,18,22,24]$

$$
\begin{aligned}
y\left(t-\tau_{j}(t)\right) \cong y_{N}(t) & =X\left(t-\tau_{j}(t)\right) M Y \\
& =X(t) L\left(-\tau_{j}(t)\right) M Y
\end{aligned}
$$

so that

$$
L\left(\tau_{j}(t)\right)=\left[\begin{array}{ccccc}
\left(\begin{array}{l}
0 \\
0
\end{array}\right)\left(-\tau_{j}(t)\right)^{0} & \left(\begin{array}{l}
1 \\
0
\end{array}\right)\left(-\tau_{j}(t)\right)^{1} & \left(\begin{array}{l}
2 \\
0
\end{array}\right)\left(-\tau_{j}(t)\right)^{2} & \ldots & \left(\begin{array}{c}
N \\
0
\end{array}\right)\left(-\tau_{j}(t)\right)^{N} \\
0 & \left(\begin{array}{l}
1 \\
1
\end{array}\right)\left(-\tau_{j}(t)\right)^{0} & \left(\begin{array}{l}
2 \\
1
\end{array}\right)\left(-\tau_{j}(t)\right)^{1} & \ldots & \left(\begin{array}{c}
N \\
1
\end{array}\right)\left(-\tau_{j}(t)\right)^{N-1} \\
0 & 0 & \left(\begin{array}{l}
2 \\
2
\end{array}\right)\left(-\tau_{j}(t)\right)^{0} & \ldots & \left(\begin{array}{c}
N \\
2
\end{array}\right)\left(-\tau_{j}(t)\right)^{N-2} \\
\vdots & \vdots & \vdots & & \vdots \\
0 & 0 & 0 & \cdots & \left(\begin{array}{c}
N \\
N
\end{array}\right)\left(-\tau_{j}(t)\right)^{0}
\end{array}\right]
$$


Note that the matrix $X\left(t-\tau_{j}(t)\right)$ can be written as

$X\left(t-\tau_{j}(t)\right)=X(t) L\left(-\tau_{j}(t)\right)$

By substituting the relations Eqs. 7, 8, and 9 into Eq. 1, we have the matrix equation

$$
\begin{aligned}
& {\left[X(t) T-P_{1}(t) X(t)-\sum_{j=2}^{m} P_{j}(t) X(t) L\left(-\tau_{j}(t)\right)\right] M Y} \\
& \quad=P_{o}(t)
\end{aligned}
$$

and by placing the collocation points defined by

$t_{i}=a+\frac{b-a}{N} i, \quad i=0,1, \ldots, N$.

in Eq. 10, the compact form of the obtained matrix equations system

$$
\left[X T-P_{1} X-\sum_{j=2}^{m} P_{j}(t) \bar{X} \bar{L}\left(-\tau_{j}\right)\right] M Y=P_{o}
$$

where

$$
\begin{aligned}
X= & {\left[\begin{array}{c}
X\left(t_{o}\right) \\
X\left(t_{1}\right) \\
\vdots \\
X\left(t_{N}\right)
\end{array}\right]=\left[\begin{array}{ccccc}
1 & t_{o} & t_{o}^{2} & \cdots & t_{o}^{N} \\
1 & t_{1} & t_{1}^{2} & \cdots & t_{1}^{N} \\
\vdots & \vdots & \vdots & & \vdots \\
1 & t_{N} & t_{N}^{2} & \cdots & t_{N}^{N}
\end{array}\right] } \\
P_{o}= & {\left[\begin{array}{c}
L\left(-\tau_{j}\left(t_{o}\right)\right) \\
P_{o}\left(t_{o}\right) \\
P_{o}\left(t_{1}\right) \\
\vdots \\
P_{o}\left(t_{N}\right)
\end{array}\right], \bar{L}\left(-\tau_{j}\right)=\left[\begin{array}{c}
\left.\left.t_{1}\right)\right) \\
\vdots \\
L\left(-\tau_{j}\left(t_{N}\right)\right)
\end{array}\right] } \\
P_{o} & =\operatorname{diag}\left[P_{j}\left(t_{o}\right), P_{j}\left(t_{1}\right), \ldots, P_{j}\left(t_{N}\right)\right], j=1,2, \ldots, m \\
X & =\operatorname{diag}\left[X\left(t_{o}\right), X\left(t_{1}\right), \ldots, X\left(t_{N}\right)\right],
\end{aligned}
$$

\section{Morgan-Voyce matrix method}

The fundamental matrix Eq. 11 of Eq. 1 can be expressed in the form

$W Y=P_{o} \Leftrightarrow\left[W ; \mathrm{P}_{o}\right]$

where

$$
\begin{gathered}
W=\left[w_{p q}\right]=\left[X T-P_{1} X-\sum_{j=2}^{m} P_{j}(t) \bar{X} \bar{L}\left(-\tau_{j}\right)\right] M \\
p, q=0,1, \ldots, N .
\end{gathered}
$$

By using the relation Eq. 7, we obtain the corresponding matrix form to the initial condition $y(a)=\lambda$ as

$$
U Y=\lambda \Leftrightarrow[U ; Y]
$$

$U=X(a) M=\left[u_{00}, u_{01}, \ldots, u_{0 N}\right]$

Consequently, in order to get the approximate solution of Eq. 1 subject to $y(a)=\lambda$, we replace the row matrix in Eq. 13 by the last row(or any row) of the augmented matrix in Eq. 12; then, we obtain the result matrix

$\left[\tilde{W} ; \tilde{P}_{o}\right] \Leftrightarrow \tilde{W} Y=\tilde{P}_{o}$

If $\operatorname{rank} \tilde{W}=\operatorname{rank}\left[\tilde{W} ; \tilde{P}_{o}\right]=N+1$, then we can write, $Y=(\tilde{W})^{-1} \tilde{P}_{o}$. Thus the matrix, $Y$ (thereby the MorganVoyce coefficients $\left.y_{o}, y_{1}, \ldots, y_{N}\right)$ is uniquely determined; thus Eq. 1 has a unique solution.

\section{Error analysis}

In this section, an error analysis will be presented for the Morgan-Voyce polynomial solution in Eq. 16 with the residual error function $[4,8,9,13,21,22,28,31,36]$. In addition, we will improve the Morgan-Voyce polynomial solution $y_{N}(t)$ with the aid of the residual error function.

Firstly, we consider the operator Eq. 1, under the initial condition $y(a)=\lambda$,

$$
\begin{aligned}
& L[y(t)]=g(t) \\
& L[y(t)]=y^{\prime}(t)-P_{o}(t)-P_{1}(t) y(t)-\sum_{j=2}^{m} P_{j}(t) y\left(t-\tau_{j}(t)\right) .
\end{aligned}
$$

Here, $y_{N}(t)$ is the approximate solution of the problem and satisfies the problem

$$
\left\{\begin{array}{l}
L\left[y_{N}(t)\right]=g(t)+R_{N}(t), \quad a \leq t \leq b, \\
y_{N}(t)=\lambda
\end{array}\right.
$$

Also, the residual function of the Morgan-Voyce polynomial approximation $y_{N}(t)$ is defined as

$R_{N}(t)=L\left[y_{N}(t)\right]-g(t)$.

If we know the exact solution $y(t)$, then the error function is calculated as the difference between the approximate and the exact solutions defined by

$e_{N}(t)=y(t)-y_{N}(t)$

By using the Eqs. 15, 16, 17 and 18, we get the error problem

$$
\begin{aligned}
L\left[e_{N}(t)\right] & =L[y(t)]-L\left[y_{N}(t)\right]=-R_{N}(t) . \\
e_{N}(a) & =0 .
\end{aligned}
$$

such that 
By solving the error problem in Eq. 19 with the method presented in Sect. 3, we get the approximation $e_{N, M}(t)$ to $e_{N}(t)$ as follows

$e_{N, M}(t)=\sum_{n=0}^{M} a_{n}^{*} b_{n}(t), \quad(M \geq N)$.

Consequently, by means of the polynomials $y_{N}(t)$ and $e_{N, M}(t),(M \geq N)$, we obtain the corrected Morgan-Voyce polynomial solution $y_{N, M}(t)=y_{N}(t)+e_{N, M}(t)$. Here, $e_{N}(t)=y(t)-y_{N}(t), \quad E_{N, M}(t)=e_{N}(t)-e_{N, M}(t)=$ $y(t)-y_{N, M}(t)$ and $e_{N, M}(t)$ denote the error function, the corrected error function and the estimated error function, respectively.

If the exact solution of Eq. 1 can not been known, then the absolute errors $\left|e_{N}\left(t_{i}\right)\right|=\left|y\left(t_{i}\right)-y_{N}\left(t_{i}\right)\right|,\left(a \leq t_{i} \leq b\right)$ are not computed. However, the absolute errors $\left|e_{N}\left(t_{i}\right)\right|=\left|y\left(t_{i}\right)-y_{N}\left(t_{i}\right)\right|,\left(a \leq t_{i} \leq b\right)$ can be estimated by using the absolute error function $\left|e_{N, M}(t)\right|$.

$$
\begin{aligned}
& P_{o}=\left[\begin{array}{l}
0 \\
5 \\
4 \\
2
\end{array}\right], P_{1}=\left[\begin{array}{lll}
0 & 0 & 0 \\
0 & \frac{1}{4} & 0 \\
0 & 0 & 1
\end{array}\right], P_{2}=\left[\begin{array}{ccc}
-1 & 0 & 0 \\
0 & -1 & 0 \\
0 & 0 & -1
\end{array}\right], P_{3}=\left[\begin{array}{lll}
0 & 0 & 0 \\
0 & \frac{1}{2} & 0 \\
0 & 0 & 1
\end{array}\right] \\
& X(t)=\left[\begin{array}{lll}
1 & t & t^{2}
\end{array}\right] \\
& T=\left[\begin{array}{lll}
0 & 1 & 0 \\
0 & 0 & 2 \\
0 & 0 & 0
\end{array}\right], M=\left[\begin{array}{lll}
1 & 1 & 1 \\
0 & 1 & 3 \\
0 & 0 & 1
\end{array}\right], X=\left[\begin{array}{c}
X(0) \\
X\left(\frac{1}{2}\right) \\
X(1)
\end{array}\right]=\left[\begin{array}{lll}
1 & 0 & 0 \\
1 & \frac{1}{2} & \frac{1}{4} \\
1 & 1 & 1
\end{array}\right] \\
& \bar{X}=\left[\begin{array}{ccc}
X(0) & 0 & 0 \\
0 & X\left(\frac{1}{2}\right) & 0 \\
0 & 0 & X(1)
\end{array}\right]=\left[\begin{array}{ccccccccc}
1 & 0 & 0 & 0 & 0 & 0 & 0 & 0 & 0 \\
0 & 0 & 0 & 1 & \frac{1}{2} & \frac{1}{4} & 0 & 0 & 0 \\
0 & 0 & 0 & 0 & 0 & 0 & 1 & 1 & 1
\end{array}\right] \\
& \bar{L}\left(-\tau_{2}\left(t_{i}\right)\right)=\left[\begin{array}{ccc}
1 & 0 & 0 \\
0 & 1 & 0 \\
0 & 0 & 1 \\
1 & -\frac{1}{4} & \frac{1}{16} \\
0 & 1 & -\frac{1}{2} \\
0 & 0 & 1 \\
1 & -1 & 1 \\
0 & 1 & -2 \\
0 & 0 & 1
\end{array}\right], \quad \bar{L}\left(-\tau_{3}\left(t_{i}\right)\right)=\left[\begin{array}{ccc}
1 & -1 & 1 \\
0 & 1 & -2 \\
0 & 0 & 1 \\
1 & -\frac{5}{4} & \frac{25}{16} \\
0 & 1 & -\frac{5}{2} \\
0 & 0 & 1 \\
1 & -2 & 4 \\
0 & 1 & -4 \\
0 & 0 & 1
\end{array}\right]
\end{aligned}
$$

subject to the initial condition $y(0)=-1$. The exact solution of this equation is $y(t)=t-1$. First of all, let us determine the collocation points by the formula $t_{i}=a+$ $\frac{b-a}{N} i, i=0,1, \ldots, N$ for $a=0, b=1$, and $m=3, N=2$. Therefore the collocation points are obtained as $t_{o}=0, t_{1}=\frac{1}{2}, t_{2}=1$. By Eq. 11, the fundamental matrix equation of this problem is written as

$$
\left[X T-P_{1} X-\sum_{j=2}^{3} P_{j}(t) \bar{X} \bar{L}\left(-\tau_{j}\right)\right] M Y=P_{o}
$$

where 
Table 1 Numerical results of the exact, approximate and corrected solutions of

Example 2 for some $N$ values

\begin{tabular}{|c|c|c|c|c|c|c|c|}
\hline \multirow[t]{2}{*}{$\mathrm{t}$} & \multirow[b]{2}{*}{ Exact } & \multicolumn{2}{|c|}{$N=3, M=4$} & \multicolumn{2}{|c|}{$N=4, M=5$} & \multicolumn{2}{|c|}{$N=12, M=13$} \\
\hline & & Appr. & Corrected & Appr. & Corrected & Appr. & Corrected \\
\hline 0 & 1.00000 & 1.00000 & 1.00000 & 1.00000 & 1.00000 & 1.00000 & 1.00000 \\
\hline 0.1 & 1.22140 & 1.39581 & 1.20219 & 1.20219 & 1.22571 & 1.22140 & 1.22140 \\
\hline 0.2 & 1.49182 & 1.75739 & 1.46663 & 1.46663 & 1.49689 & 1.49182 & 1.49182 \\
\hline 0.3 & 1.82212 & 2.11993 & 1.79678 & 1.79678 & 1.82697 & 1.82212 & 1.82212 \\
\hline 0.4 & 2.22554 & 2.51864 & 2.20151 & 2.20151 & 2.23024 & 2.22554 & 2.22554 \\
\hline 0.5 & 2.71828 & 2.98872 & 2.69510 & 2.69510 & 2.72299 & 2.71828 & 2.71828 \\
\hline 0.6 & 3.32012 & 3.56539 & 3.29724 & 3.29724 & 3.32478 & 3.32012 & 3.32012 \\
\hline 0.7 & 4.05520 & 4.28383 & 4.03301 & 4.03301 & 4.05954 & 4.05520 & 4.05520 \\
\hline 0.8 & 4.95303 & 5.17927 & 4.93292 & 4.93292 & 4.95683 & 4.95303 & 4.95303 \\
\hline 0.9 & 6.04965 & 6.28689 & 6.03286 & 6.03286 & 6.05299 & 6.04965 & 6.04965 \\
\hline 1 & 7.38906 & 7.64191 & 7.37414 & 7.37414 & 7.39236 & 7.38906 & 7.38906 \\
\hline
\end{tabular}

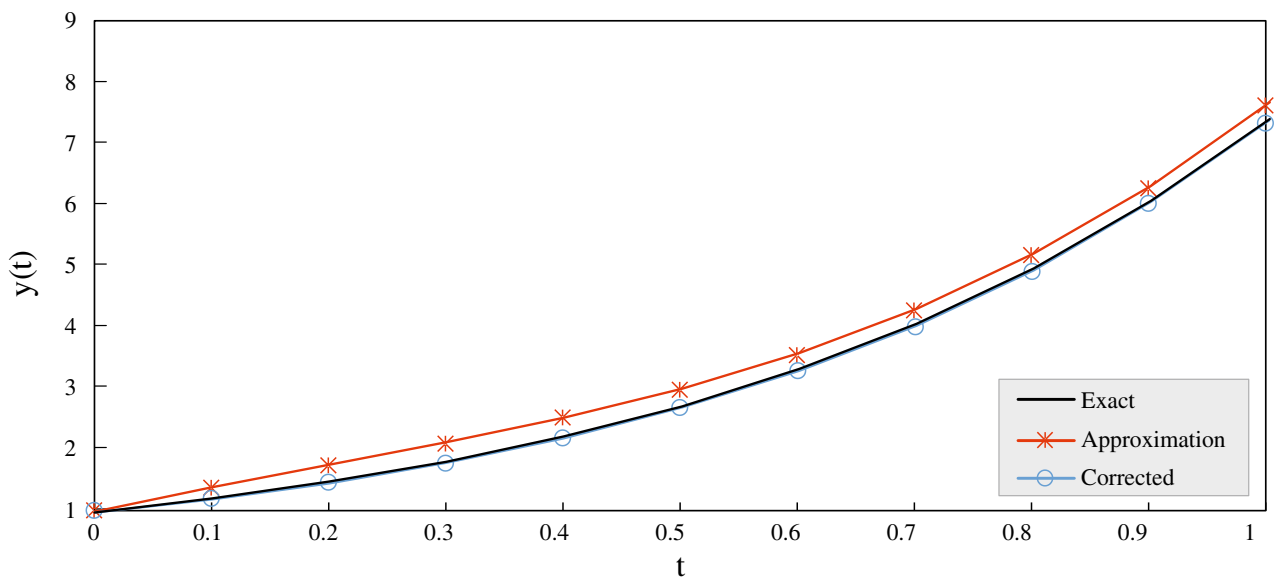

Fig. 1 Exact, approximate and corrected solutions of Example 2 for $N=3$

Fig. 2 Exact, approximate and corrected solutions of Example 2 for $N=4$

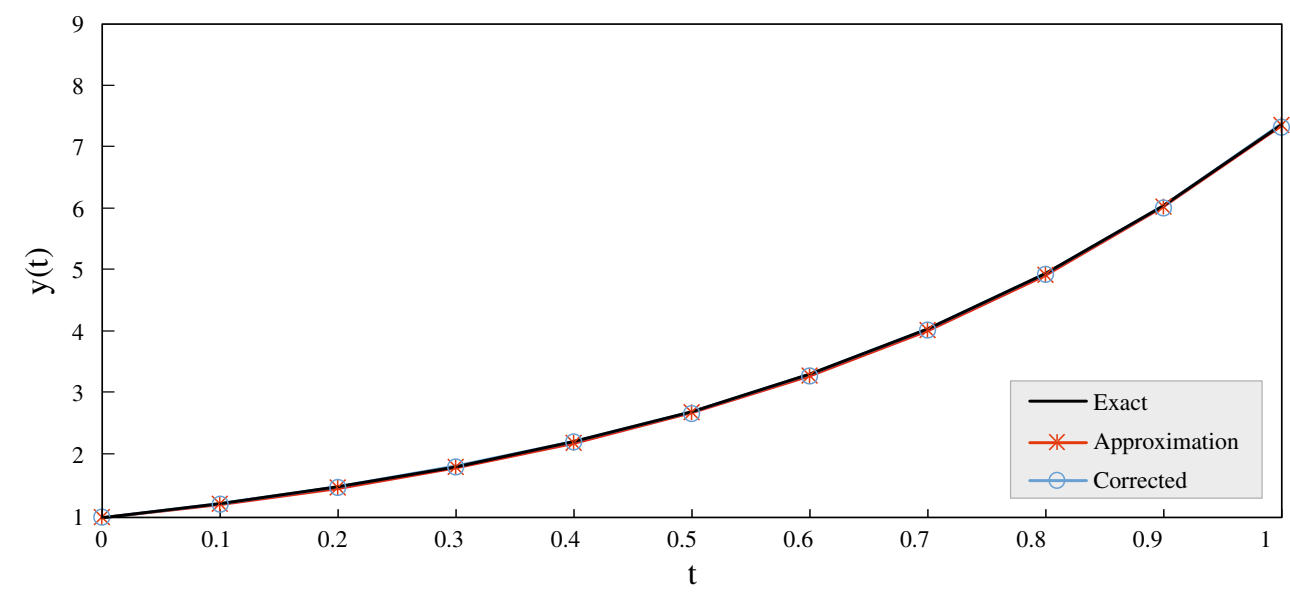

The augmented matrix of the fundamental matrix equation is computed as

$$
\left[W ; P_{o}\right]=\left[\begin{array}{ccc|c}
1 & 2 & 4 & 0 \\
0.25 & 1.75 & 5.46875 & 1.25 \\
-1 & 0 & 2 & -1
\end{array}\right]
$$


Table 2 Comparison of the absolute errors and corrected absolute errors of Example 2

Fig. 3 Comparison of the absolute error with the corrected absolute error for $N=3$

Fig. 4 Comparison of the absolute error with the corrected absolute error for $N=4$

\begin{tabular}{|c|c|c|c|c|c|c|}
\hline \multirow[t]{2}{*}{$\mathrm{t}$} & \multicolumn{2}{|l|}{$N=3, M=4$} & \multicolumn{2}{|l|}{$N=4, M=5$} & \multicolumn{2}{|c|}{$N=12, M=13$} \\
\hline & Appr. & Corrected & Appr. & Corrected & Appr. & Corrected \\
\hline 0 & $7.99361 \mathrm{e}-15$ & $6.21725 e-15$ & $3.10862 \mathrm{e}-15$ & $1.02141 \mathrm{e}-14$ & $2.02061 \mathrm{e}-14$ & $4.97380 \mathrm{e}-14$ \\
\hline 0.1 & $1.74411 \mathrm{e}-01$ & $1.92085 \mathrm{e}-02$ & $1.92085 \mathrm{e}-02$ & $4.30490 \mathrm{e}-03$ & $5.60576 \mathrm{e}-11$ & $2.89457 \mathrm{e}-12$ \\
\hline 0.2 & $2.65564 \mathrm{e}-01$ & $2.51946 \mathrm{e}-02$ & $2.51946 \mathrm{e}-02$ & $5.06186 \mathrm{e}-03$ & $5.52192 \mathrm{e}-11$ & $2.88503 \mathrm{e}-12$ \\
\hline 0.3 & $2.97810 \mathrm{e}-01$ & $2.53429 \mathrm{e}-02$ & $2.53429 \mathrm{e}-02$ & $4.85123 e-03$ & $5.51801 \mathrm{e}-11$ & $2.87947 \mathrm{e}-12$ \\
\hline 0.4 & $2.93098 \mathrm{e}-01$ & $2.40357 \mathrm{e}-02$ & $2.40357 \mathrm{e}-02$ & $4.69433 e-03$ & $5.49143 e-11$ & $2.87148 \mathrm{e}-12$ \\
\hline 0.5 & $2.70441 \mathrm{e}-01$ & $2.31845 \mathrm{e}-02$ & $2.31845 \mathrm{e}-02$ & $4.71136 \mathrm{e}-03$ & $5.42593 e-11$ & $2.86038 \mathrm{e}-12$ \\
\hline 0.6 & $2.45269 \mathrm{e}-01$ & $2.28805 \mathrm{e}-02$ & $2.28805 \mathrm{e}-02$ & $4.66159 \mathrm{e}-03$ & $5.29470 \mathrm{e}-11$ & $2.80753 \mathrm{e}-12$ \\
\hline 0.7 & $2.28632 \mathrm{e}-01$ & $2.21878 \mathrm{e}-02$ & $2.21878 \mathrm{e}-02$ & $4.33963 e-03$ & $5.04476 \mathrm{e}-11$ & $2.68496 \mathrm{e}-12$ \\
\hline 0.8 & $2.26233 \mathrm{e}-01$ & $2.01130 \mathrm{e}-02$ & $2.01130 \mathrm{e}-02$ & $3.79602 \mathrm{e}-03$ & $4.58762 \mathrm{e}-11$ & $2.45759 \mathrm{e}-12$ \\
\hline 0.9 & $2.37243 \mathrm{e}-01$ & $1.67888 \mathrm{e}-02$ & $1.67888 \mathrm{e}-02$ & $3.34318 \mathrm{e}-03$ & $3.76135 \mathrm{e}-11$ & $2.08455 \mathrm{e}-12$ \\
\hline 1.0 & $2.52855 \mathrm{e}-01$ & $1.49208 \mathrm{e}-02$ & $1.49208 \mathrm{e}-02$ & $3.29924 \mathrm{e}-03$ & $2.63132 \mathrm{e}-11$ & $1.53477 \mathrm{e}-12$ \\
\hline
\end{tabular}
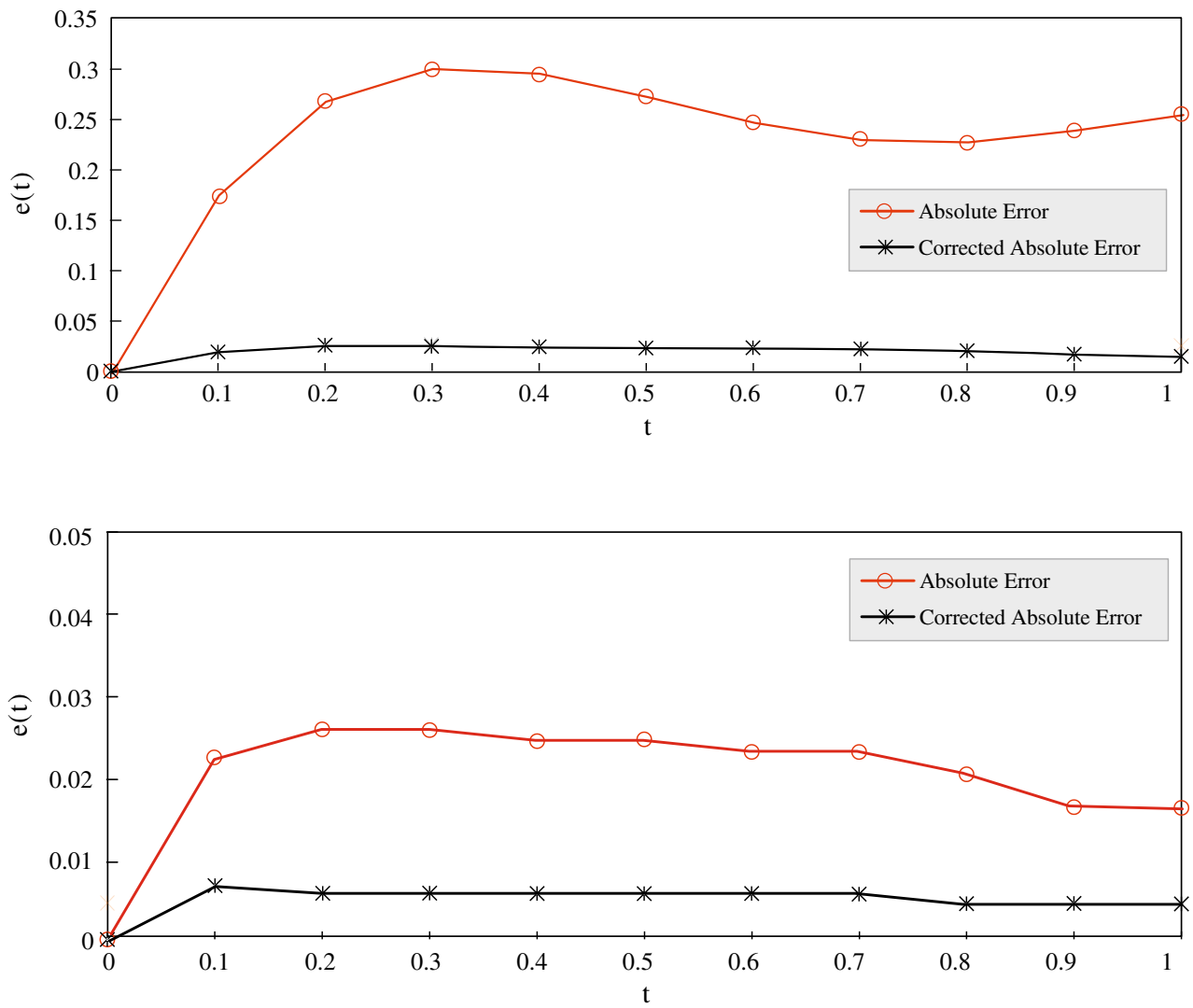

and the augmented matrix for initial condition is obtained as

$$
[U ; \lambda]=\left[\begin{array}{lll}
1 & 1 & 1 \mid-1
\end{array}\right]
$$

By using the procedure in Sect. 3, we obtain the approximate solution as

$$
y_{2}(t)=t-1
$$

which is the exact solution.
Example 2 Consider the differential equation with variable delay $t^{2}$

$$
2 y^{\prime}(t)-t y(t)+t e^{2 t^{2}} y\left(t-t^{2}\right)=4 e^{2 t}, \quad 0 \leq t \leq 1
$$

subject to the initial condition $y(0)=1$. The exact solution of this equation is $y(t)=e^{2 t}$. The fundamental matrix equation is

$$
\left[X T-P_{1} X-P_{2} \bar{X} \bar{L}\left(-\tau_{2}\left(t_{i}\right)\right)\right] M Y=P_{o} .
$$


Table 3 Numerical results of the exact, approximate and corrected solutions of Example 3 for some $N$ values

\begin{tabular}{|c|c|c|c|c|c|c|c|}
\hline \multirow[t]{2}{*}{$\mathrm{t}$} & \multirow[b]{2}{*}{ Exact } & \multicolumn{2}{|c|}{$N=3, M=4$} & \multicolumn{2}{|c|}{$N=4, M=5$} & \multicolumn{2}{|c|}{$N=12, M=13$} \\
\hline & & Appr. & Corrected & Appr. & Corrected & Appr. & Corrected \\
\hline 0 & 1.00000 & 1.00000 & 1.00000 & 1.00000 & 1.00000 & 1.00000 & 1.00000 \\
\hline 0.1 & 0.90484 & 0.90675 & 0.90500 & 0.90500 & 0.90485 & 0.90484 & 0.90484 \\
\hline 0.2 & 0.81873 & 0.82159 & 0.81894 & 0.81894 & 0.81874 & 0.81873 & 0.81873 \\
\hline 0.3 & 0.74082 & 0.74401 & 0.74103 & 0.74103 & 0.74083 & 0.74082 & 0.74082 \\
\hline 0.4 & 0.67032 & 0.67350 & 0.67052 & 0.67052 & 0.67033 & 0.67032 & 0.67032 \\
\hline 0.5 & 0.60653 & 0.60956 & 0.60672 & 0.60672 & 0.60654 & 0.60653 & 0.60653 \\
\hline 0.6 & 0.54881 & 0.55168 & 0.54900 & 0.54900 & 0.54882 & 0.54881 & 0.54881 \\
\hline 0.7 & 0.49659 & 0.49936 & 0.49677 & 0.49677 & 0.49660 & 0.49659 & 0.49659 \\
\hline 0.8 & 0.44933 & 0.45209 & 0.44950 & 0.44950 & 0.44934 & 0.44933 & 0.44933 \\
\hline 0.9 & 0.40657 & 0.40937 & 0.40673 & 0.40673 & 0.40658 & 0.40657 & 0.40657 \\
\hline 1 & 0.36788 & 0.37069 & 0.36803 & 0.36803 & 0.36789 & 0.36788 & 0.36788 \\
\hline
\end{tabular}

Fig. 5 Exact, approximate and corrected solutions of Example 3 for $N=3$

Fig. 6 Exact, approximate and corrected solutions of Example 3 for $N=4$
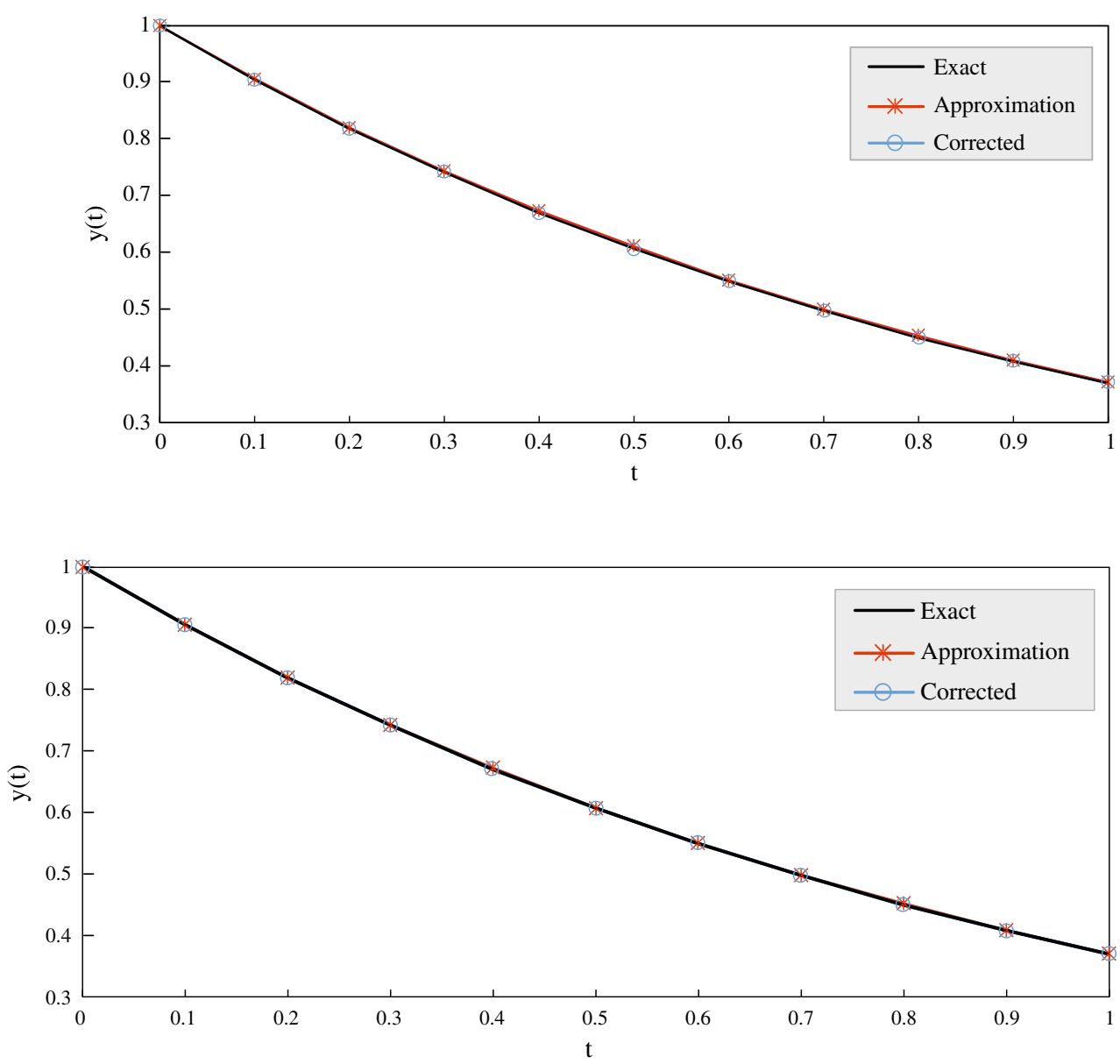

After the collocation points substituted into this matrix equation, we solve the system and we obtain the solutions in the form 4 of Example 2 for $N=3,4,12$ in the interval $[0,1]$ Table 1.

Now, we will give the exact, approximation, and corrected solutions of Example 2 for $N=3,4$ in Figs. 1 and 2 , respectively.
The absolute and corrected errors of Example 2 in Table 2 are compared for $N=3,4$ in Figs. 3 and 4, respectively.

Example 3 Consider the delay differential equation having variable delays $\ln (t+1)$ and $t^{2}$ 
Table 4 Comparison of the absolute errors and corrected absolute errors of Example 3

\begin{tabular}{|c|c|c|c|c|c|c|}
\hline \multirow[t]{2}{*}{$\mathrm{t}$} & \multicolumn{2}{|l|}{$N=3, M=4$} & \multicolumn{2}{|l|}{$N=4, M=5$} & \multicolumn{2}{|c|}{$N=12, M=13$} \\
\hline & Appr. & Corrected & Appr. & Corrected & Appr. & Corrected \\
\hline 0 & 0 & 0 & $2.22045 \mathrm{e}-16$ & $2.22045 \mathrm{e}-16$ & $4.44089 \mathrm{e}-16$ & $4.44089 \mathrm{e}-16$ \\
\hline 0.1 & $1.91653 e-03$ & $1.57584 \mathrm{e}-04$ & $1.57584 \mathrm{e}-04$ & $1.15985 \mathrm{e}-05$ & $1.16573 \mathrm{e}-13$ & $2.98650 \mathrm{e}-14$ \\
\hline 0.2 & $2.86131 \mathrm{e}-03$ & $2.06131 \mathrm{e}-04$ & $2.06131 \mathrm{e}-04$ & $1.35662 \mathrm{e}-05$ & $1.13909 \mathrm{e}-13$ & $2.95319 \mathrm{e}-14$ \\
\hline 0.3 & $3.19084 \mathrm{e}-03$ & $2.07981 \mathrm{e}-04$ & $2.07981 \mathrm{e}-04$ & $1.30496 \mathrm{e}-05$ & $1.12577 \mathrm{e}-13$ & $2.89768 \mathrm{e}-14$ \\
\hline 0.4 & $3.17959 \mathrm{e}-03$ & $1.97746 \mathrm{e}-04$ & $1.97746 \mathrm{e}-04$ & $1.25881 \mathrm{e}-05$ & $1.09690 \mathrm{e}-13$ & $2.83107 \mathrm{e}-14$ \\
\hline 0.5 & $3.02786 \mathrm{e}-03$ & $1.90112 \mathrm{e}-04$ & $1.90112 \mathrm{e}-04$ & $1.24366 \mathrm{e}-05$ & $1.05804 \mathrm{e}-13$ & $2.74225 \mathrm{e}-14$ \\
\hline 0.6 & $2.86876 \mathrm{e}-03$ & $1.86905 \mathrm{e}-04$ & $1.86905 \mathrm{e}-04$ & $1.21434 \mathrm{e}-05$ & $1.01363 e-13$ & $2.64233 e-14$ \\
\hline 0.7 & $2.77470 \mathrm{e}-03$ & $1.83479 \mathrm{e}-04$ & $1.83479 \mathrm{e}-04$ & $1.14580 \mathrm{e}-05$ & $9.62008 \mathrm{e}-14$ & $2.50355 \mathrm{e}-14$ \\
\hline 0.8 & $2.76306 e-03$ & $1.74494 \mathrm{e}-04$ & $1.74494 \mathrm{e}-04$ & $1.06297 \mathrm{e}-05$ & $9.02611 \mathrm{e}-14$ & $2.35367 \mathrm{e}-14$ \\
\hline 0.9 & $2.80153 e-03$ & $1.59153 \mathrm{e}-04$ & $1.59153 \mathrm{e}-04$ & $1.01563 \mathrm{e}-05$ & $8.32667 e-14$ & $2.20934 \mathrm{e}-14$ \\
\hline 1 & $2.81276 \mathrm{e}-03$ & $1.45931 \mathrm{e}-04$ & $1.45931 \mathrm{e}-04$ & $1.00352 \mathrm{e}-05$ & $7.82152 \mathrm{e}-14$ & $1.96509 \mathrm{e}-14$ \\
\hline
\end{tabular}

Fig. 7 Comparison of the absolute error with the corrected absolute error for $N=3$

Fig. 8 Comparison of the absolute error with the corrected absolute error for $N=4$
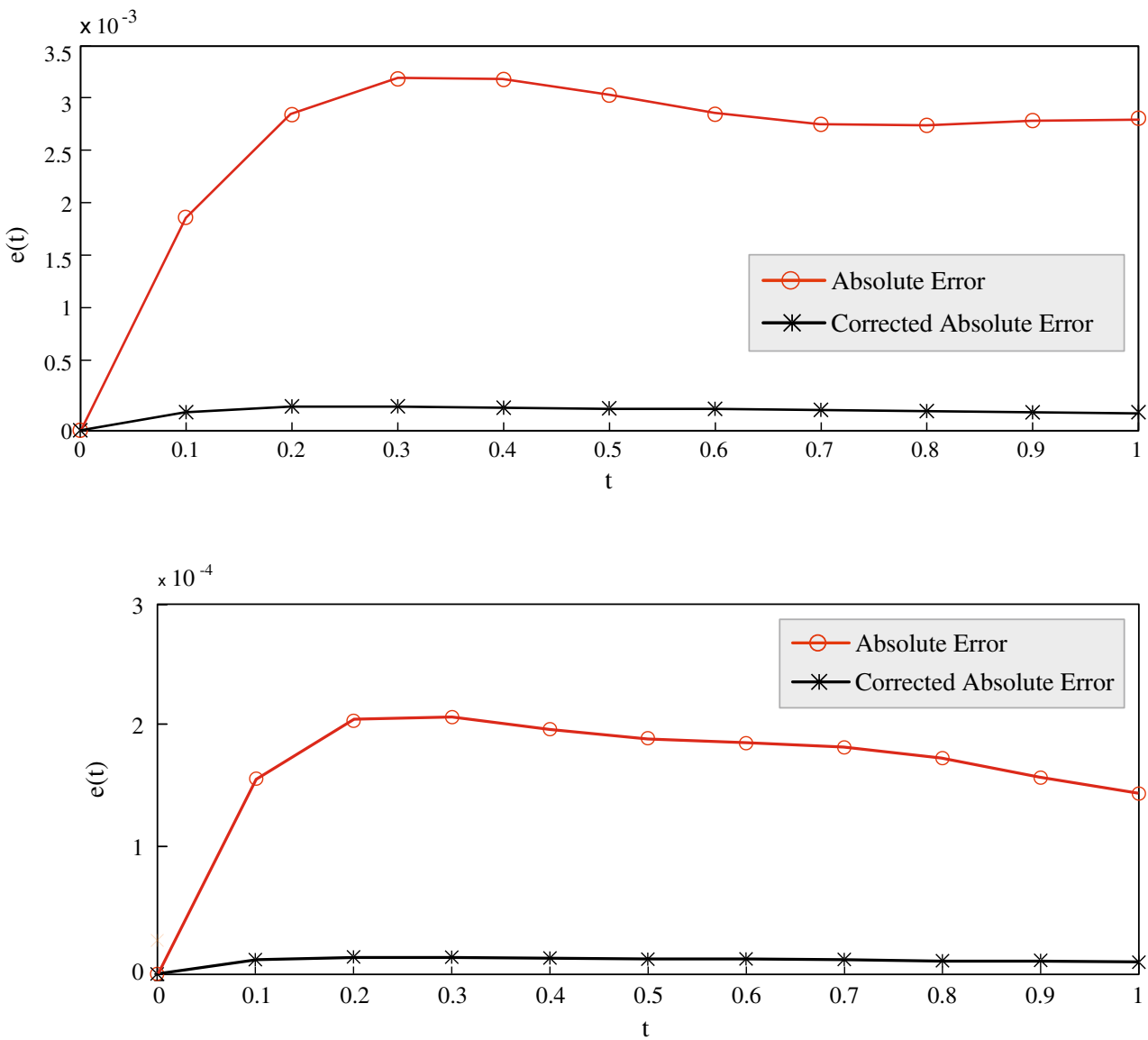

$$
\begin{aligned}
y^{\prime}(t)= & \left(t^{2}+t-1\right) e^{-t}-t y(t-\ln (t+1))-e^{-t^{2}} y\left(t-t^{2}\right) \quad\left[X T-P_{1} X-P_{2} \bar{X} \bar{L}\left(-\tau_{2}\left(t_{i}\right)\right)-P_{3} \bar{X} \bar{L}\left(-\tau_{3}\left(t_{i}\right)\right)\right] M Y=P_{o} . \\
& +y(t), \quad 0 \leq t \leq 1
\end{aligned}
$$

subject to the initial condition $y(0)=1$. The exact solution of this equation is $y(t)=e^{-t}$. The fundamental matrix equation is
After the collocation points substituted into this matrix equation, we can solve the system and we obtain the 
Table 5 Numerical results of the Exact, Present and HTL solutions of Example 4 for $N=$ 6 value

Fig. 9 Comparison of the exact, present and HTL solutions of Example 4 for $N=6$ value

\begin{tabular}{llllll}
\hline $\mathrm{t}$ & Exact & Present & Abs. error & HTL & Abs. error \\
\hline 0.0 & 1.0000000 & 1.0000000 & $5.55112 \mathrm{e}-15$ & 1.000000067 & $6.70000 \mathrm{e}-08$ \\
0.2 & 0.8187308 & 0.8187339 & $3.10453 \mathrm{e}-06$ & 0.807836989 & $1.08938 \mathrm{e}-02$ \\
0.4 & 0.6703200 & 0.6703221 & $2.03288 \mathrm{e}-06$ & 0.649394632 & $2.09254 \mathrm{e}-02$ \\
0.6 & 0.5488116 & 0.5488127 & $1.09160 \mathrm{e}-06$ & 0.529079726 & $1.97319 \mathrm{e}-02$ \\
0.8 & 0.4493290 & 0.4493294 & $4.48652 \mathrm{e}-07$ & 0.436772222 & $1.25567 \mathrm{e}-02$ \\
1.0 & 0.3678794 & 0.3678793 & $1.14014 \mathrm{e}-07$ & 0.361610346 & $6.26909 \mathrm{e}-03$ \\
1.2 & 0.3011942 & 0.3011936 & $5.72331 \mathrm{e}-07$ & 0.298780813 & $2.41340 \mathrm{e}-03$ \\
1.4 & 0.2465970 & 0.2465960 & $9.17880 \mathrm{e}-07$ & 0.249314192 & $2.71723 \mathrm{e}-03$ \\
1.6 & 0.2018965 & 0.2018953 & $1.22873 \mathrm{e}-06$ & 0.212885438 & $1.09889 \mathrm{e}-02$ \\
1.8 & 0.1652989 & 0.1652975 & $1.43489 \mathrm{e}-06$ & 0.173619567 & $8.32068 \mathrm{e}-03$ \\
2.0 & 0.1353353 & 0.1353338 & $1.44145 \mathrm{e}-06$ & 0.078902496 & $5.64328 \mathrm{e}-02$ \\
\hline
\end{tabular}

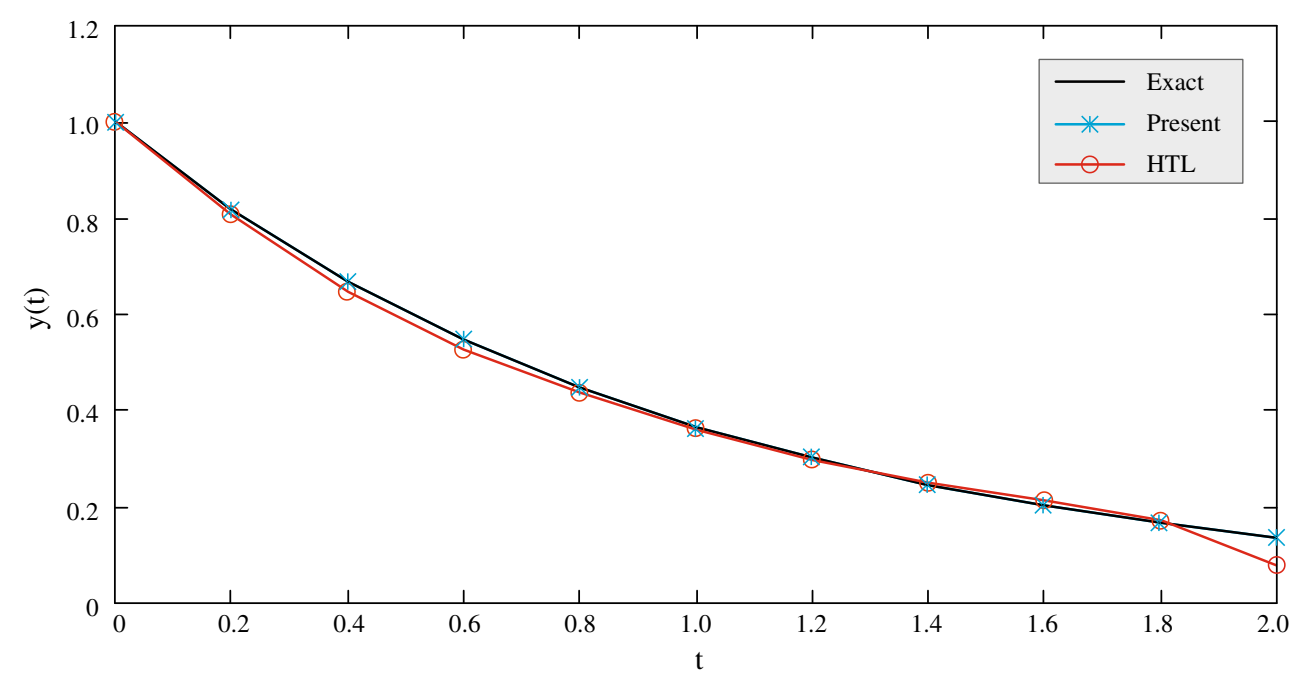

Fig. 10 RMSE values for $\mathrm{N}=$ $1,2, \ldots, 100$ for Examples 2, 3 and 4

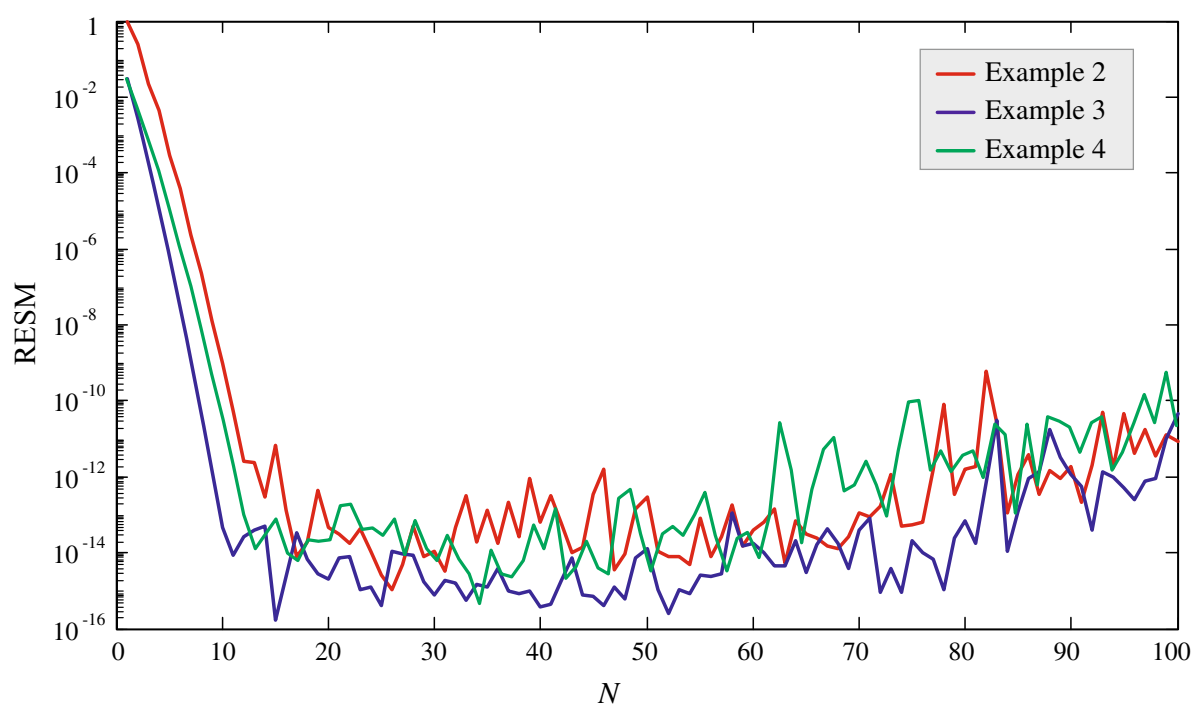


solutions in the form 4 of Example 3 for $N=3,4,12$ in the interval $[0,1]$ Table 3.

All exact, approximation, and corrected solutions of Example 3 for $N=3,4$ are given in Fig. 5 and 6, respectively. The absolute and corrected errors of Example 3 in Table 4 are compared for $N=3,4$ in Figs. 7 and 8, respectively.

Example 4 Consider the following delay differential equation [7] having variable delay $\ln \left(t^{2}+1\right)$

$y^{\prime}(t)=\left(t^{2}+1\right) e^{-t}-y\left(t-\ln \left(t^{2}+1\right)\right)-y(t), \quad 0 \leq t \leq 2$

subject to the initial condition $y(0)=1$. The exact solution of this equation is $y(t)=e^{-t}$.

Similarly, we can solve this problem by present method and we obtain the solutions in the form 4 of Example 4 for $N=6$ in the interval $[0,2]$. Then, we also compare the present solutions and Hybrid Taylor-Lucas Method [7] (HTL) solutions in Table 5. The present method has been shown to be suitable as graphically for nonhomogeneous differential equation with variable delays in Fig. 9.

In order to better define the solution space of the problems of Examples 2, 3 and 4 described above, the $N$ value has been scanned up 1 to 100 . The root-mean-square error (RMSE) value of the solution obtained for each $N$ value is calculated and shown in Fig. 10. When $N>12$, the RMSE values of the solutions of both problems are oscillated between $10^{-10}$ and $10^{-16}$. The reason of these oscillations is the truncation errors in the calculations.

\section{Conclusion}

A new approach using the Morgan-Voyce polynomials to solve numerically the first-order nonhomogeneous differential equations with variable delays is presented in this study. An error analysis technique based on residual function is also developed our problems. If the exact solution of the problem is not known, by using this technique it is possible to estimate the error function and also to reduce the error due to the residual function. It is seen that, the accuracy improves, when $N$ is increased. To compute our solutions and error functions, we have written a code in Matlab and calculated all computations by means of this code.

Consequently, the present method has been shown to be convenient, reliable and effective for solving the first-order nonhomogeneous differential equation with variable delays.

Open Access This article is distributed under the terms of the Creative Commons Attribution 4.0 International License (http:// creativecommons.org/licenses/by/4.0/), which permits unrestricted use, distribution, and reproduction in any medium, provided you give appropriate credit to the original author(s) and the source, provide a link to the Creative Commons license, and indicate if changes were made.

\section{References}

1. Abd-Elhameed, W.M., Youssri, Y.H., Doha, E.H.: A novel operational matrix method based on shifted Legendre polynomials for solving second-order boundary value problems involving singular, singularly perturbed and Bratu-type equations. Math. Sci. 9, 93-102 (2015)

2. Akyüz, A., Sezer, M.: A Chebyshev collocation method for the solution of linear integro-differential equations. Int. J. Comput. Math. 72, 491-507 (1999)

3. Ardjouni, A., Djoudi, A.: Fixed points and stability in linear neutral differential equations with variable delays. Nonlinear Anal. Theory Methods Appl. 74, 2062-2070 (2011)

4. Bahş1, M.M., Çevik, M., Sezer, M.: Orthoexponential polynomial solutions of delay pantograph differential equations with residual error estimation. Appl. Math. Comput. 271, 11-21 (2015)

5. Bahş1, M.Mustafa, Bahşı, Ayşe Kurt, Çevik, Mehmet, Sezer, Mehmet: Improved Jacobi matrix method for the numerical solution of Fredholm integro-differential-difference equations. Math. Sci. 10, 83-93 (2016)

6. Balc1, M.A., Sezer, M.: Hybrid Euler-Taylor matrix method for solving of generalized linear Fredholm integro-differential difference equations. Appl. Math. Comput. 273, 33-41 (2016)

7. Bayku, N., Sezer, M.: Hybrid Taylor-Lucas collocation method for numerical solution of high-order pantograph type delay differential equations with variables delays. Appl. Math. Inf. Sci. 11, 1795-1801 (2017)

8. Çelik, İ: Approximate calculation of eigenvalues with the method of weighted residuals-collocation method. Appl. Math. Comput. 160, 401-410 (2005)

9. Çelik, İ.: Collocation method and residual correction using Chebyshev series. Appl. Math. Comput. 174, 910-920 (2006)

10. Dix, J.G.: Asymptotic behavior of solutions to a first-order differential equation with variable delays. Comput. Math. Appl. 50, 1791-1800 (2005)

11. Djordjevic, G.B., Milovanovic, G.V.: Special classes of polynomials. Univ. Nis Fac. Technol. Leskovac 58, 11-18 (2014)

12. Elahi, Zaffer, Akram, Ghazala, Siddiqi, Shahid Saeed: Numerical solution for solving special eighth-order linear boundary value problems using Legendre Galerkin method. Math. Sci. 10, 201-209 (2016)

13. Erdem, K., Yalçinbaş, S., Sezer, M.: A Bernoulli polynomial approach with residual correction for solving mixed linear Fredholm integro-differential-difference equations. J. Differ. Equ. Appl. 19, 1619-1631 (2013)

14. Erfanian, M., Zeidabadi, H.: Using of Bernstein spectral Galerkin method for solving of weakly singular Volterra-Fredholm integral equations. Math. Sci. (2018). https://doi.org/10.1007/s40096018-0249-1

15. Fortuna, L., Frasca, M.: Generating passive systems from recursively defined polynomials. Int. J. Circuits Syst. Signal Process. 6, 179-188 (2012)

16. Gülsu, M., Sezer, M.: Approximations to the solution of linear Fredholm integrodifferential-difference equation of high order. J. Franklin Inst. 343, 720-737 (2006)

17. Gürbüz, B., Sezer, M., Güler, C.: Laguerre collocation method for solving Fredholm integro-differential equations with functional arguments. J. Appl. Math. 2014, 48 (2014) 
18. Işik, O.R., Güney, Z., Sezer, M.: Bernstein series solutions of pantograph equations using polynomial interpolation. J. Differ. Equ. Appl. 18, 357-374 (2012)

19. Ilhan, O., Sahin, N.: On Morgan-Voyce polynomials approximation for linear differential equations. Int. J. Comput. Math. 72, 491-507 (2014)

20. Jin, C., Luo, J.: Fixed points and stability in neutral differential equations with variable delays. Proc. Am. Math. Soc. 136, 909-918 (2008)

21. Kürkçü, Ö., Aslan, E., Sezer, M.: A numerical approach with error estimation to solve general integro-differential-difference equations using Dickson polynomials. Appl. Math. Comput. 276, 324-339 (2016)

22. Kürkçü, Ö., ASLAN, E., Sezer, M.: A novel collocation method based on residual error analysis for solving integro-differential equations using hybrid dickson and taylor polynomials. Sains Malays. 46, 335-347 (2017)

23. Le, Anh Minh, Chau, Dang Dinh: Asymptotic equilibrium of integro-differential equations with infinite delay. Math. Sci. 9, 189-192 (2015)

24. Mollaoğlu, T., Sezer, M.: A numerical approach with residual error estimation for eolution of high-order linear differentialdifference equations by using gegenbauer polynomials. Sains Malays. 46, 335-347 (2017)

25. Nouri, K., Torkzadeh, L., Mohammadian, S.: Hybrid Legendre functions to solve differential equations with fractional derivatives. Math. Sci. (2018). https://doi.org/10.1007/s40096-0180251-7

26. Oğuz, C., Sezer, M.: Chelyshkov collocation method for a class of mixed functional integro-differential equations. Appl. Math. Comput. 259, 943-954 (2015)

27. Olach, R.: Positive periodic solutions of delay differential equations. Appl. Math. Lett. 26, 1141-1145 (2013)

28. Oliveira, F.A.: Collocation and residual correction. Numer. Math. 36, 27-31 (1980)
29. Sezer, M., Akyüz-Daşcıoglu, A.: A Taylor method for numerical solution of generalized pantograph equations with linear functional argument. J. Comput. Appl. Math. 200, 217-225 (2007)

30. Singh, Randhir, Wazwaz, Abdul-Majid: Numerical solutions of fourth-order Volterra integro-differential equations by the Greens function and decomposition method. Math. Sci. 10, 159-166 (2016)

31. Shahmorad, S.: Numerical solution of the general form linear Fredholm-Volterra integro-differential equations by the Tau method with an error estimation. Appl. Math. Comput. 167, 1418-1429 (2005)

32. Stoll, T., Tichy, R.: Diophantine equations for Morgan-Voyce and other modified orthogonal polynomials. Math. Slovaca 58, 11-18 (2008)

33. Swamy, M.N.S.: Further properties of Morgan-Voyce polynomials. Int. J. Comput. Math. 72, 491-507 (1968)

34. Wang, H.: Positive periodic solutions of functional differential equations. J. Differ. Equ. 202, 354-366 (2004)

35. Yüzbaş1, Ş., Sezer, M.: An exponential approximation for solutions of generalized pantograph-delay differential equations. Appl. Math. Model. 37, 9160-9173 (2013)

36. Yüzbaş1, Ş., Şahin, N., Sezer, M.: A Bessel polynomial approach for solving linear neutral delay differential equations with variable coefficients. J. Adv. Res. Differ. Equ. 3, 81-101 (2011)

37. Zhang, Bo: Fixed points and stability in differential equations with variable delays. Nonlinear Anal. Theory Methods Appl. 63, 233-242 (2005)

38. Zhao, D.: New criteria for stability of neutral differential equations with variable delays by fixed points method. Adv. Differ. Equ. 2011, 48 (2011)

\section{Publisher's Note}

Springer Nature remains neutral with regard to jurisdictional claims in published maps and institutional affiliations. 